Research Article

\title{
Service Life Prediction of Precast Concrete Structures Exposed to Chloride Environment
}

\author{
Dawei Zhang $\mathbb{D}^{1},{ }^{1}$ Yu Zeng, ${ }^{1}$ Mingshan Fang, ${ }^{2}$ and Weiliang Jin ${ }^{1}$ \\ ${ }^{1}$ Institute of Structural Engineering, Zhejiang University, Hangzhou, China \\ ${ }^{2}$ Zhejiang Communications Investment Group Co.,Ltd., Hangzhou, China \\ Correspondence should be addressed to Dawei Zhang; dwzhang@zju.edu.cn \\ Received 2 January 2019; Revised 5 March 2019; Accepted 3 April 2019; Published 2 May 2019 \\ Academic Editor: Mariano Angelo Zanini \\ Copyright (C) 2019 Dawei Zhang et al. This is an open access article distributed under the Creative Commons Attribution License, \\ which permits unrestricted use, distribution, and reproduction in any medium, provided the original work is properly cited. \\ Chloride-induced corrosion is widely accepted as one of the primary causes of premature deterioration for concrete structures in \\ marine or deicing salt environment. For precast concrete (PC) structures, such durability problems may even be severer because \\ defects in joint areas, e.g., cracks caused by grout shrinkage and improper construction, can accelerate chloride ion transportation \\ process and may cause the interface shear failure when subjected to seismic load. By applying the path probability model (PPM) \\ and reliability theory, a probabilistic framework was proposed to predict three limit states of PC structures, including corrosion \\ initiation, serviceability limit state, and ultimate limit state. Using Monte Carlo simulation, a beam-to-column joint was further \\ analyzed to illustrate the differences between PC structures and those cast in situ. The analysis indicates that corrosion initiation \\ and serviceability limit state are sensitive to chloride diffusivity at connection area, and the higher pitting factor can significantly \\ influence the bearing capacities of PC structures.
}

\section{Introduction}

The performance of engineering concrete structures can inevitably deteriorate due to shrinkage, creep [1], carbonation $[2,3]$, or ingression of other corrosive agents $[4,5]$. Among these factors, chloride-induced corrosion is dominant for structures in marine or deicing salt environment. As chloride ions penetrate through concrete cover and accumulate at the steel surface, corrosion gradually initiates. Expansive corrosion products can further induce cracks and even reduce the shear bearing capacity of components and joint significantly [6-10] (shown in Figure 1). Some key points can be defined based on the mechanisms of corrosion and thus divide the process into different stages [11-14]. One is corrosion initiation, the moment when chloride concentration at the steel surface reaches the threshold and triggers corrosion. Besides, serviceability limit state (SLS), indicated by crack width or deflection, and ultimate limit state (ULS), which is closely related to safety, can also be chosen as the criteria of structural failure.

Compared to cast in situ concrete, precast concrete could be of better quality since the mixture ratio and curing conditions are better controlled in factories [15-17]. Such advancement enables concrete cover to better block detrimental corrosive agents and thus is beneficial for durability. However, defects may form in the field-cast connection area between components due to grout shrinkage, improper construction, etc., and this could lead to an increase in permeability at the joint [18]. Consequently, the chloride penetration process will be accelerated, initiating earlier steel corrosion and triggering severer degradation around the interface, which is exactly where the maximum shear force should occur under seismic impact (shown in Figure 2). Therefore, the durability of PC structures is still a problem worth paying attention to when they are applied in the marine environment. The aforementioned differences are concluded in Table 1.

As is widely known, one of the prerequisites to achieve durability design is the precise prediction of structure's service life [19]. This could be achieved by experience, comparisons of similar projects, accelerated tests, or mathematical models, according to ACI [20]. Among all these methods, mathematical modeling is the most accepted one owing to its concision and accuracy [14, 20-24], and the 


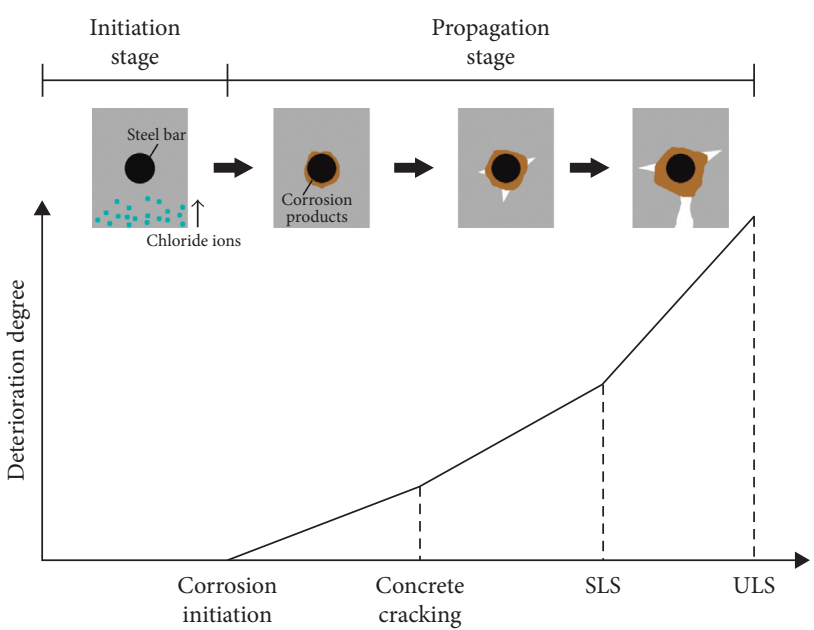

FIgURE 1: Deterioration process of RC structures in the chloride environment.

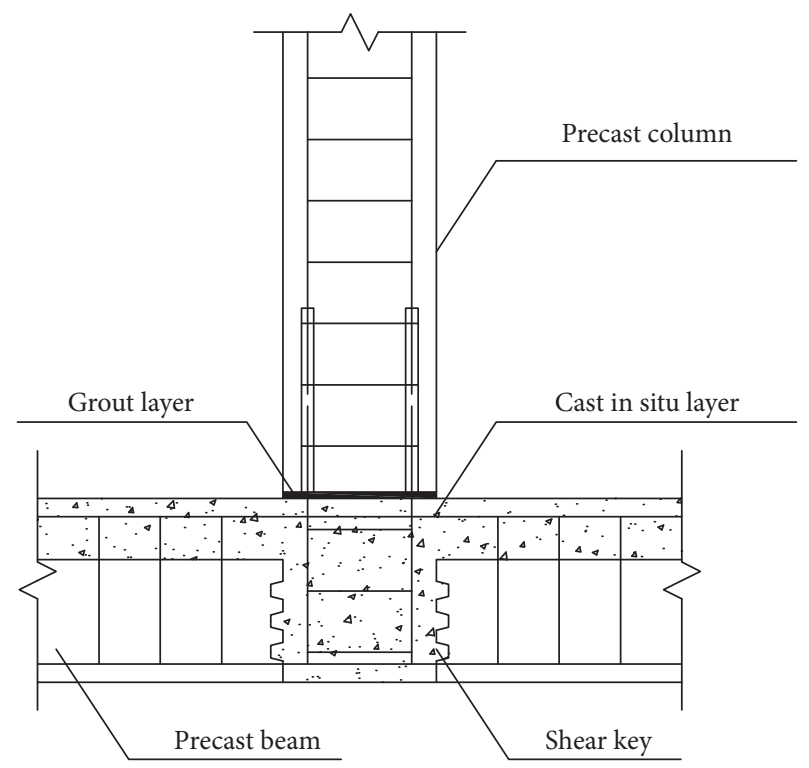

Figure 2: Typical beam-column joint in PC frames.

TABle 1: Comparison between cast in situ RC structures and PC structures.

\begin{tabular}{lcc}
\hline Features & $\begin{array}{c}\text { Cast in situ RC } \\
\text { structures }\end{array}$ & PC structures \\
\hline $\begin{array}{l}\text { Concrete quality } \\
\text { Connection between } \\
\text { components }\end{array}$ & $\begin{array}{c}\text { Lower and more } \\
\text { scattered }\end{array}$ & $\begin{array}{c}\text { Higher and } \\
\text { better controlled }\end{array}$ \\
$\begin{array}{l}\text { Morrosion } \\
\text { distribution }\end{array}$ & $\begin{array}{c}\text { Relatively more } \\
\text { uniform }\end{array}$ & $\begin{array}{c}\text { Potential defects } \\
\text { Shear failure modes concentrate } \\
\text { in earthquakes }\end{array}$ \\
\hline
\end{tabular}

uncertainty in deterioration process can also be considered using fuzzy theory [25] or well-developed reliability theory [26-33]. However, most of these researches focused on the corrosion initiation, without considering the following propagation stages and their links to the initiation of corrosion. Meanwhile, none of them discussed the difference of deterioration mechanism and the service life between PC structures and those cast in situ, which brings obstacles to a better understanding and prediction of the service life of PC structures.

In this paper, a probabilistic method is proposed to predict all the above limit states of PC structures. Then, parametric analysis is conducted to address the special features of PC beam-to-column joint and their influence on the service life.

\section{Prediction Methods and Models}

For PC structures, the definition of limit states and service life prediction methods are generally regarded the same as those of cast in situ RC structures, while more attention should be paid on the effect of localized steel pitting corrosion caused by higher diffusivity of chloride ions around the connection interface. Meanwhile, as is mentioned in the former session, inevitable uncertainty should also be considered or the prediction result is invalid. Therefore, all the three limit states are analyzed in a probabilistic method and the corresponding service life is predicted on the basis of well-developed reliability theory.

2.1. Service Life Prediction Based on Reliability. According to reliability theory [34], the failure probability $p_{\mathrm{f}}(T)$ should not be larger than the acceptable level, $p_{\mathrm{f}, \mathrm{a}}$, or the structure is no longer reliable, so the service life of a structure can be defined as the smallest $T$ to satisfy the following equation:

$$
p_{\mathrm{f}}(T) \geq p_{\mathrm{f}, \mathrm{a}}=\Phi(-\beta),
$$

where $\Phi()$ is the cumulative distribution function (CDF) of Gaussian distribution and $\beta$ is the reliability index.

In practice, the target reliability index (acceptable failure probability) is determined in accordance with engineering standards or other references, so service life prediction can be largely interpreted as the analysis of time-variant failure probability. Now that the definition of failure varies with limit states and the exact expressions of failure probability may be different. For corrosion initiation, SLS and ULS are expressed as equations (2), (3) and (4), respectively.

$$
\begin{aligned}
p_{\mathrm{f}}(t) & =P\left[G_{1}(t) \leq 0\right] \\
& =P\left[c_{\mathrm{cr}}-c_{\mathrm{x}}(t) \leq 0\right](\text { corrosion initiation), } \\
p_{\mathrm{f}}(t) & =P\left[G_{2}(t) \leq 0\right]=P\left[\omega_{\mathrm{cr}}-\omega(t) \leq 0\right](\mathrm{SLS}), \\
p_{\mathrm{f}}(T) & =P\left[G_{3}(t) \leq 0\right]=P[R(t)-S(t) \leq 0](\mathrm{ULS}),
\end{aligned}
$$

where $P$ is the probability of an event; $c_{\mathrm{x}}(t)$ is the chloride concentration at the surface of steel bars, and $c_{\mathrm{cr}}$ is the critical concentration to initiate corrosion; $\omega(t)$ is the maximum width of corrosion-induced cracks, and $\omega_{\mathrm{cr}}$ is the corresponding threshold; and $R(t)$ is the resistance, and $S(t)$ is the structural response under external loads. Obviously, 
models relating to chloride transportation, steel corrosion, corrosion-induced crack propagation, and strength deterioration are all necessary to describe the deterioration process. The following sections will introduce these models and the framework to integrate them together.

2.2. Models for Chloride Transportation. Chloride ion transportation in concrete is quite complicated, containing physical processes such as diffusion, convection, migration, capillary suction, and so on [4]. In normal conditions, diffusion plays a dominant role, and it can be described by Fick's law. Although analysis can be directly carried out based on the original partial differential equation, using numerical methodologies such as Crank-Nicolson method [24], the workload may be impractically heavy when conducting Monte Carlo simulation. Therefore, explicit solutions are still essential in the probabilistic method. The earliest used and simplest model can be expressed as [35]

$$
C_{\mathrm{x}}=C_{\mathrm{s}}\left[1-\operatorname{erf}\left(\frac{x}{2 \sqrt{D t}}\right)\right]
$$

where $C_{\mathrm{x}}$ denotes the chloride ion concentration at the surface of steel bar and $C_{s}$ is the concentration at the structure surface; $x$ is the thickness of concrete cover in $\mathrm{mm}$, and $D$ is the diffusion coefficient in $\mathrm{mm}^{2} / \mathrm{s}$; and erf () refers to the error function. Based on this, some modified models are proposed to consider depth of convection zone [36], reduction of chloride diffusivity [37], accumulation of surface chloride [38], binding effect and the influence of defects [39]. Due to the lack of verification and vagueness in parameters, some newly built models may not work and be expected, even though more factors are included. In this paper, the widely accepted model in engineering standard [20] is used:

$$
C_{\mathrm{x}}=k t\left[\left(1+\frac{x^{2}}{2 D t}\right) \operatorname{erfc}\left(\frac{x}{2 \sqrt{D t}}\right)-\left(\frac{x}{\sqrt{\pi D t}}\right) e^{-\left(x^{2} / 4 D t\right)}\right],
$$

where $k$ is the constant in the linear buildup model of surface concentration and $\operatorname{erfc}()$ is the complementary error function. According to the field investigation, the surface chloride ion accumulation process is not infinite. Once the time reaches the upper bound, the surface chloride concentration stays constant and equation (5) can be directly used.

\subsection{Models for Steel Corrosion and Crack Propagation.} Generally speaking, corrosion is an oxidation process in which metal loses electrons and gains a positive valence. According to Faraday's law, the mass loss is proportional to the total charge [40], so there is a linear relationship between corrosion rate and current density [26], and the corrosion depth can be further calculated by integration:

$$
p(t)=\int_{0}^{t} v(t) d t=0.0116 \int_{0}^{t} i_{\text {corr }}(t) d t,
$$

where $v$ is the corrosion rate in $\mathrm{mm} / \mathrm{a}$ and $i_{\text {corr }}$ is the corrosion current density in $\mu \mathrm{A} / \mathrm{cm}^{2}$. By multiplying $p$ with the pitting coefficient $\alpha$, which varies from $4-8$, the maximum corrosion penetration depth $p_{\max }$ can be determined. The remaining area of reinforcement $A_{\mathrm{s}, \mathrm{r}}$, as well as the corrosion level $\rho$, can be further calculated using the geometric relations in the pit configuration (see details in Appendix A) [41].

However, in real situations, it is an extremely difficult work to precisely predict $i_{\text {corr }}(t)$ since it is affected by various factors. Models were built from experience [21, 42], consideration of dominating factors in the reaction $[19,27,43,44]$, or electrochemical backgrounds [45]. Although those derived from the corrosion mechanism seem to be of higher complexity and more reliable, the requirements of input parameters may be very restricted and complicated to be practical $[4,46]$. Therefore, an empirical model is used in this paper [42]:

$$
\begin{aligned}
\ln 1.08 i_{\text {corr }}(t)= & 7.89+0.7771 \ln 1.69 \mathrm{Cl}-\frac{3006}{\operatorname{Temp}} \\
& -0.000116 R_{\mathrm{c}}+2.24 t_{\mathrm{p}}^{-0.215},
\end{aligned}
$$

where Temp is the temperature at the steel surface in degree Kelvin, which can be roughly chosen as the average temperature, since the variation of temperature in concrete is comparatively lower. $\mathrm{Cl}$ is the total chloride content at steel surface and is set as a constant, $3 \mathrm{~kg} / \mathrm{m}^{3}$, which is slightly higher than the so-called critical chloride content [47]. Similarly, the ohmic resistance of the cover concrete, $R_{\mathrm{c}}$, is also set to $1500 \mathrm{ohms}$ [42], and $t_{\mathrm{p}}$ refers to the time after corrosion initiation in year.

After substituting equation (10) into equation (7), there is no explicit solutions to the integral calculation considering the form of $i_{\text {corr }}(t)$; therefore, this process can only be achieved numerically. Thereafter, widths of corrosioninduced cracks can be obtained using the correlation between crack width and corrosion level. Generally speaking, it is linear to sectional loss $[48,49]$ or corrosion penetration depth $[36,50-52]$. In this paper, a widely accepted model [48] is used to predict crack width:

$$
\omega=K\left(\Delta A_{\mathrm{s}}-\Delta A_{\mathrm{s} 0}\right),
$$

where $K$ is the fitting constant, which is $0.0575, \Delta A_{s}$ is the steel section loss, and $\Delta A_{\mathrm{s} 0}$ is the steel loss necessary to induce cracking in $\mathrm{mm}^{2}$, which can be calculated by the following equation:

$$
\Delta A_{\mathrm{s} 0}=A_{\mathrm{s}}\left[1-\left[1-\frac{\alpha}{d_{0}}\left(7.53+9.32 \frac{x}{d_{0}}\right) 10^{-3}\right]^{2}\right],
$$

where $x$ is the thickness of the concrete cover in $\mathrm{mm}$.

2.4. Models for Shear Capacity. As is shown in Figure 3, for a typical beam-to-column joint in PC structures, shear failure could occur in precast components (columns or beams), in joint area, or at the connection interface. Among them, interface shear failure is specially considered in PC structures, according to current codes $[15,36,53]$. In practice, joint area is usually designed strong enough to avoid failure under complex stress states, so only the other two modes are considered herein. 


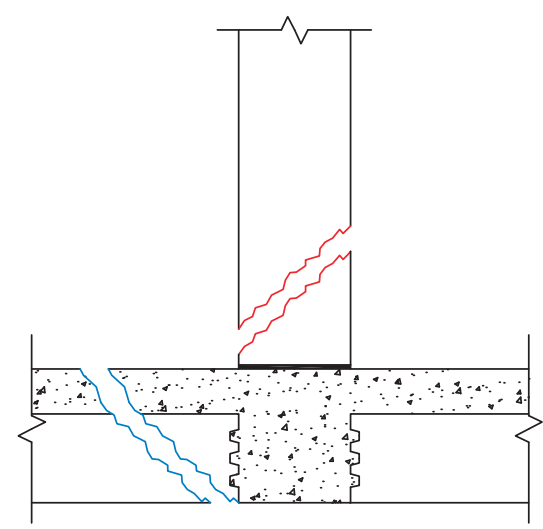

(a)

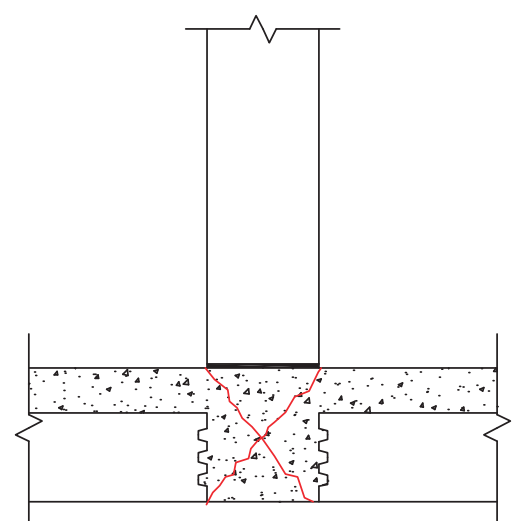

(b)

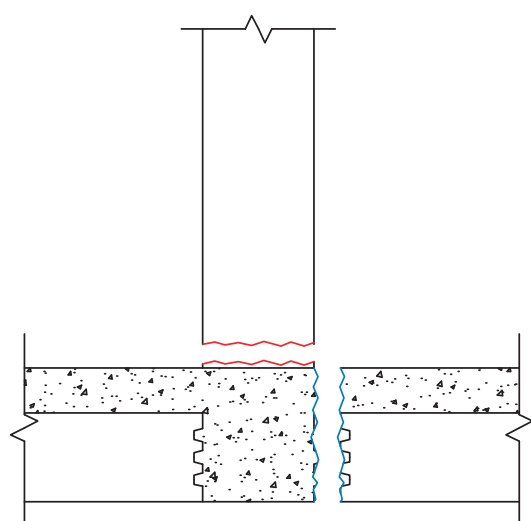

(c)

FIgURE 3: Possible shear failure modes for beam-to-column joint in PC structures. (a) Component failure. (b) Joint failure. (c) Interface failure.

For precast components, a large proportion of shear strength is provided by transverse reinforcement, and thus stirrup corrosion is much more essential than longitudinal steel corrosion when considering strength loss. In this paper, instead of ignoring the influence of relative variables and directly setting the corrosion current density as a known value [54], the corrosion level of stirrup is assumed to be the same as that of longitudinal reinforcement for simplicity.

In most engineering standards, the shear capacity of a component is expressed by

$$
V_{\text {component }}=V_{\mathrm{s}}+V_{\mathrm{c}} \text {. }
$$

The contribution of stirrups can be expressed as

$$
V_{\mathrm{s}}=\frac{A_{\mathrm{st}, \mathrm{r}}\left(1-\alpha_{\mathrm{s}} \rho\right) f_{\mathrm{yt}} h_{0}}{s}
$$

where $A_{\mathrm{st}, \mathrm{r}}$ is the total remaining area of stirrups within the distance $s ; \alpha_{\mathrm{s}}$ is the reduction factor of yield strength, which may vary from 0.5 to 2.4 [55-57], and an intermediate value, 2 , is chosen herein; and $h_{0}$ is the effective depth of the component in $\mathrm{mm}$. Shear resistance provided by concrete can be calculated using the following equation:

$$
\begin{aligned}
V_{\mathrm{c}}= & 0.8\left(\frac{0.5 \sqrt{f_{\mathrm{c}}}}{\lambda} \sqrt{1+\frac{N}{0.5 \sqrt{f_{\mathrm{c}}}\left(A_{\text {core }}+\sqrt{\zeta} A_{\text {cover }}\right)}}\right) \\
& \cdot\left(A_{\text {core }}+\sqrt{\zeta} A_{\text {cover }}\right),
\end{aligned}
$$

where $f_{\mathrm{c}}$ is the compressive strength of concrete in $\mathrm{MPa} ; \lambda$ is the shear span-depth ratio, which can be calculated as $0.5 \mathrm{l} / h_{0} ; l$ is the length of the component in $\mathrm{mm} ; N$ is the axial force in $\mathrm{N}$, which is negligible in beams; $A_{\text {core }}$ and $A_{\text {cover }}$ are the area of core concrete and cover concrete in $\mathrm{mm}^{2}$, respectively; and $\zeta$ is the strength reduction coefficient of cover concrete calculated as follows:

$$
\zeta=\frac{0.9}{\sqrt{1+600\left(W_{\mathrm{cr}} / p_{0}\right)}}
$$

where $p_{0}$ is the original perimeter of the component section in $\mathrm{mm}$ and $W_{\mathrm{cr}}$ is the total crack width in $\mathrm{mm}$.
For a corroded component, it can be assumed as the total width of corrosion-induced cracks calculated by equation (9) to simplify the prediction model.

Unlike in components, shear force can transfer across the connection interface with several mechanisms, including friction induced by axial force and clamping stress, concrete cohesion, and dowel action of reinforcement [36]. Among them, shear friction is the most widely accepted one [58], but models based on it may be too conservative [59], and an improved model that incorporates concrete cohesion in can be written as [60]

$$
V_{i}=0.11 f_{\mathrm{c}}^{0.65} A_{\mathrm{c}}+\left(A_{\mathrm{si}} f_{\mathrm{y} i}+N\right) \mu,
$$

where $A_{\mathrm{c}}$ is the sectional area of the component in $\mathrm{mm}^{2}, A_{\mathrm{s} i}$ is the total area of reinforcement across the interface in $\mathrm{mm}^{2}$, and $\mu$ is the frictional coefficient, which can be expressed as the tangent value of the frictional angel $\phi^{\prime}$. Obviously, interfacial shear strength is largely controlled by transverse reinforcement yielding, which is not reasonable when the reinforcement ratio is high enough. Precrushing failure of concrete may be dominant in this circumstance. Therefore, it is necessary to set an upper limit to the value calculated by equation (15) as

$$
V_{i} \leq 0.26 f_{\mathrm{c}} A_{\mathrm{c}} e^{\left(-0.03\left(f_{\mathrm{c}} / 10\right)^{0.9}\left(2300 / \rho_{\mathrm{c}}\right)^{1.6}\right)} \sin \left(2 \phi^{\prime}\right),
$$

where $\rho_{c}$ is the density of concrete in $\mathrm{kg} / \mathrm{m}^{3}$ and $\phi^{\prime}$ is the frictional angle mentioned before, which can be chosen between $29.4^{\circ}$ and $44.5^{\circ}$ [60]. However, the aforementioned models for the interface shear strength do not include the influence of corrosion, and no existing model has been proposed to consider this problem. Due to the similarity of the mechanism of corrosion-induced deterioration, two assumptions are made to determine the shear strength of interface with corroded transverse reinforcement. One is to consider the concrete section loss caused by cracks based on equation (14) and substitute $A_{c}$ with the remaining area $A_{c, r}$. The other is to adjust $A_{\mathrm{si}}$ and $f_{\mathrm{y} i}$, as in equation (12), to consider the variation of shear friction. Due to lack of empirical data, the effect of steel corrosion on the interface frictional coefficient is not considered in the present study. 
2.5. Models for Flexural Capacity. Although interface shear performance is specially addressed for PC structures, shear failure is not preferred due to its brittle nature and thus prevented in many codes. A more reasonable mode is ductile flexural failure, which is consistent with the results of some experimental investigations [17, 61, 62]. Despite the uneven stiffness introduced by grout sleeve and connection interface, there is little difference between the bearing capacities of precast and monolithic joints [17, 63], so the bearing capacity models proposed for corroded cast in situ components are used to evaluate the flexural performance of PC structures.

When calculating flexural capacity, the influence of axial force is nonnegligible, especially for columns, so a moment, axial force curve (M-N curve), is necessary. In the model proposed by Xin et al. [64], three important points in the curve, including axial compression point, balanced failure point, and pure bending point, are firstly determined considering factors like steel section loss, concrete cracking, bond performance deterioration, and confinement (see details in Appendix B). More interpolation points are generated using Hermite interpolation, and the explicit expression of the curve can be then realized by the Fourier fitting (Figure 4). The acceptable range of the moment can further be determined with the curve once the axial force is given.

2.6. A Probabilistic Framework. Before analyzing service life in a reliability-based approach, a framework is required to incorporate all the aforementioned models together and to consider the influence of uncertainty. For the chlorideinduced corrosion, there is a chronological sequence of limit states and thus different phases of service life could be analyzed step by step. Based on corrosion initiation prediction, which is the focus of current researches, SLS and ULS can be further analyzed using path probability model (PPM) [65].

When predicting the corrosion level at a time $t$, the initiation of corrosion can only occur in the interval $[0, t)$, otherwise the failure probability is zero. Therefore, by dividing the interval of $[0, t)$ into $n$ subintervals, $(n-1)$ paths are formed (shown in Figure 5). For each path, it is assumed that corrosion initiation occurs at $t_{i}$ and corrosion propagates in the remaining time. Now that all the paths are mutually exclusive, the distribution of corrosion level at $t$ can be calculated by simply adding the contribution of each path together according to the well-known full probability theorem.

$$
f(\rho, t)=\sum_{i=1}^{n-1} f\left(\rho \mid t_{i}\right) P\left(t_{i}\right)
$$

where $P\left(t_{i}\right)$ is the probability that corrosion initiates exactly at $t_{i} . f\left(\rho \mid t_{i}\right)$ is the distribution of corrosion level at $t$ on the condition that corrosion initiates at $t_{i}$. All of these could be calculated using Monte Carlo simulation and aforementioned models. With $f(\rho, t)$, the distribution of crack width, $f(\omega, t)$, can be further calculated by repeating total probability theorem:

$$
f(\omega, t)=\sum_{i=1}^{n-1} f\left(\omega \mid \rho_{i}\right) P\left(\rho_{i}, t\right),
$$

where $P\left(\rho_{i}, t\right)$ is the probability that the corrosion level at time $t$ is $\rho_{i}$. The distribution of residual shear and flexural capacity can be calculated in a similar way. By comparing the crack width with its threshold, whether the structure reaches its SLS can be determined and the corresponding service life can be calculated through equation (3).

Similarly, the ULS can also be determined once the external load is known. The whole analysis process can be expressed in Figure 6, and analyses in the following section are carried out accordingly.

\section{Illustrative Example}

3.1. Example Description. A typical beam-to-column joint in a precast concrete frame is chosen as an example to analyze the service life, as it contains the basic characteristic of PC structure-connection interface between components (Figure 7). Through Monte Carlo simulation with 500,000 samples, the time-variant failure probabilities, as well as the values of key performance indicators, can be obtained with the aforementioned models and the probabilistic framework. Service life prediction can further be conducted once the target reliability index $\beta$ is defined. According to the existing codes, the values for corrosion initiation and SLS are $1.3\left(p_{\mathrm{fa}}=0.097\right)$ and $1.5\left(p_{\mathrm{fa}}=0.0668\right)$, respectively $[66,67]$. Due to the lack of external shear force, which is closely related to the seismic spectrum and the response of the structure, the exact time of ultimate limit state is not predicted here. Instead, the time-variant shear and flexural capacities are analyzed in Section 3.4 and 3.5.

Since the diffusion coefficient is an important parameter for structures in the marine environment, it is particularly considered herein. For the precast part, including the column and part of the beam, the mean is $2 \times 10^{-6} \mathrm{~mm}^{2} / \mathrm{s}$, which is a typical value for ordinary concrete [26]. According to design guidelines, the cast in situ part, such as the joint area, should be of higher quality than those precasted. Therefore, the mean is taken as $1 \times 10^{-6} \mathrm{~mm}^{2} / \mathrm{s}$. As for grout interface, even though there is evidence that the defects may form there and thus increase its permeability [18], the exact influence is not clarified yet. Therefore, two diffusion coefficients, $5 \times 10^{-6} \mathrm{~mm}^{2} / \mathrm{s}$ (denoted as Case 1) and $1 \times 10^{-5} \mathrm{~mm}^{2} / \mathrm{s}$ (denoted as Case 2), are chosen to describe the diffusivity of the interface and to analyze whether they are crucial for PC structures.

Higher diffusion coefficient around the interface can trigger earlier corrosion in a small region and thus increases the degree of local corrosion due to the existence of large cathode. Therefore, $\alpha$ in equation (8) is chosen as 8 for the interface. For precast components, $\alpha$ is taken as 4 . Other parameters, including mean value and distribution parameters, are determined in reference to engineering codes or published research papers.

The distributions of other input parameters are summarized in Table 2. 


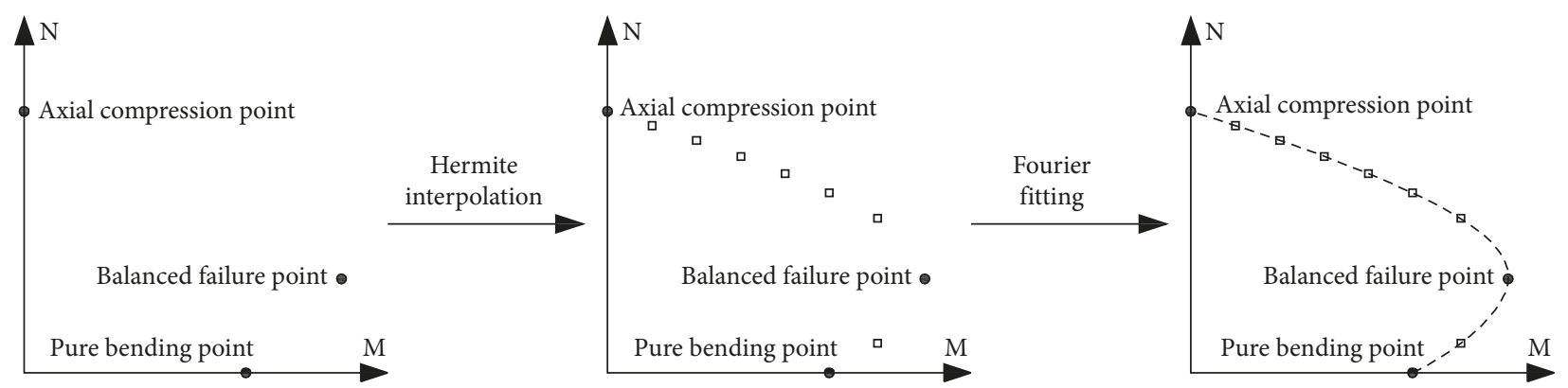

FIGURE 4: Bearing capacity analysis procedure for corroded components [64].

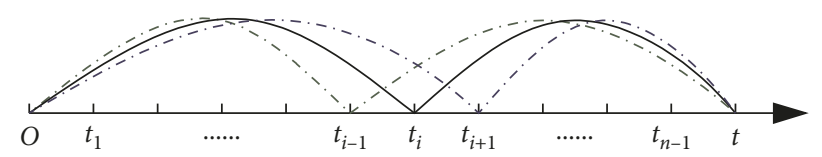

FIgURE 5: An illustrative figure of the path probability model.

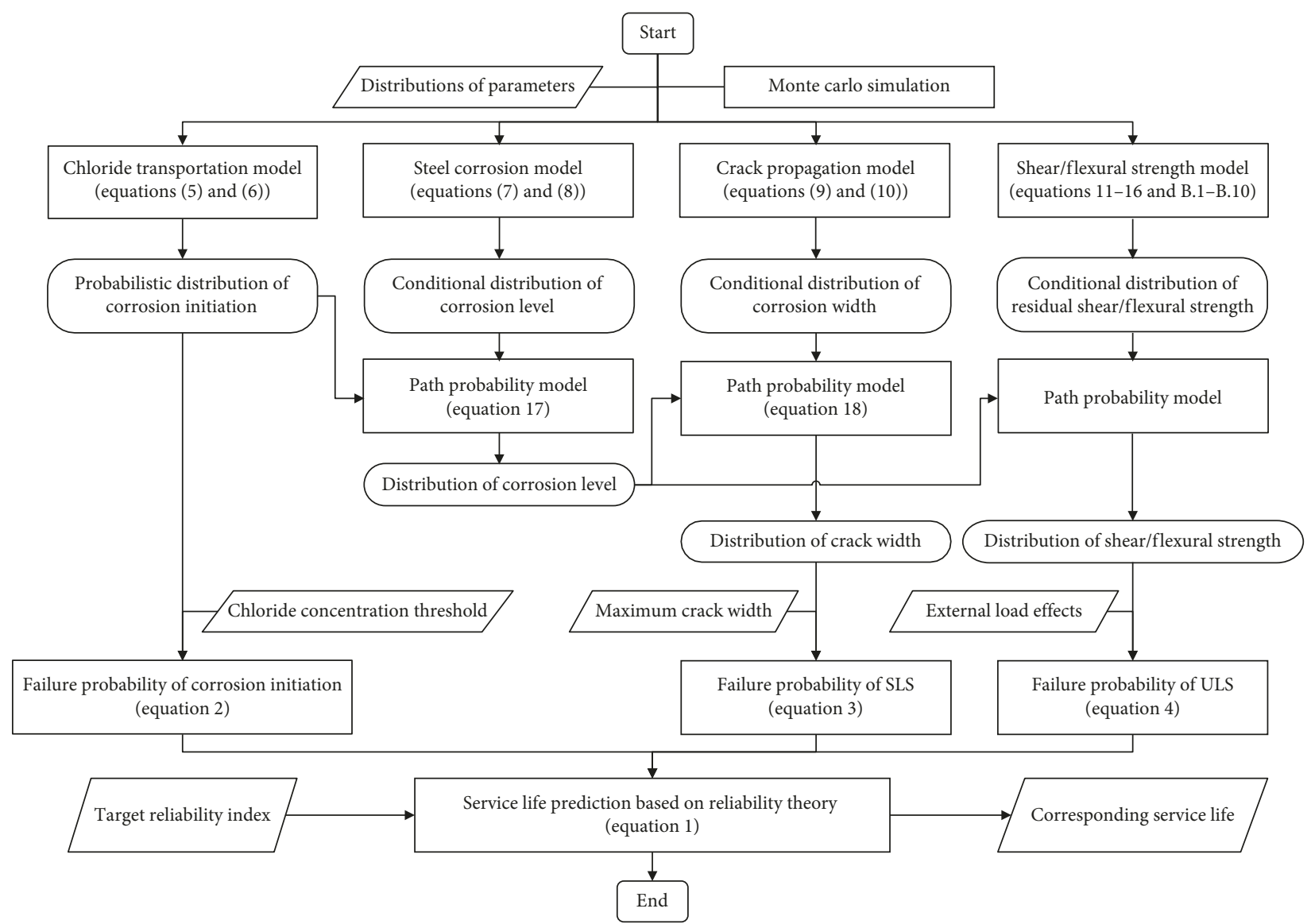

FIgURE 6: The probabilistic framework to incorporate models of each deterioration stage.

3.2. Prediction of Corrosion Initiation. As is shown in Figure 8 , in the first several years, the failure probability stays in an extremely low level, revealing that the concrete cover can effectively block the penetration of chloride ions during this period. After reaching a certain point, the failure probability increases dramatically and then slowly approaches the upper bound, 1.0. All the four groups share a similar trend, indicating that the distribution type of parameters can directly influence the shape of the curve, while the exact value varies with the inputs.

Using the defined threshold, the times of corrosion initiation can be determined, and they are 10.5, 7.3, 4.7, and 3.6 years for each group, respectively. Obviously, higher diffusion coefficient represents lower resistivity, resulting in 


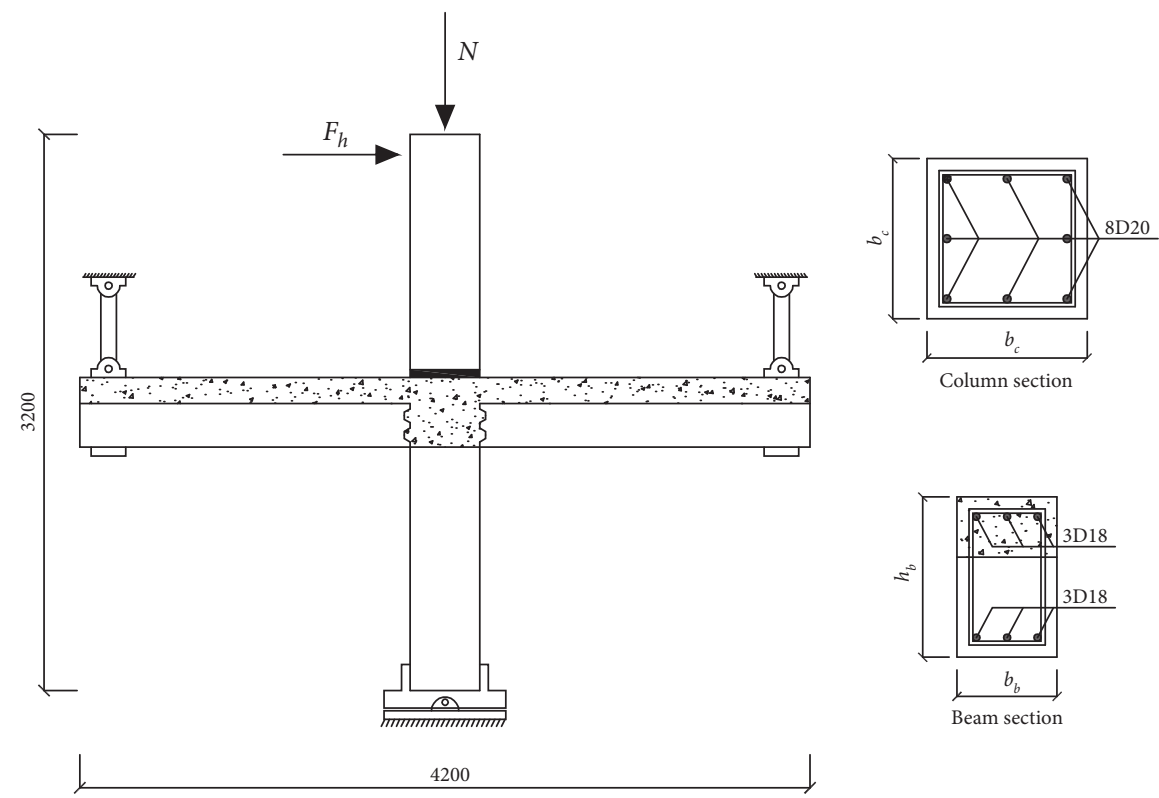

FIgURE 7: Beam-to-column joint configuration.

TABle 2: Distributions of the input parameters.

\begin{tabular}{|c|c|c|c|c|c|}
\hline Parameter & Unit & Mean & $\mathrm{COV}$ & Distribution & Reference \\
\hline Accumulation coefficient of surface chloride, $k$ & $\% / \mathrm{a}$ & 0.04 & 0.5 & Log-normal & {$[24,27]$} \\
\hline Maximum accumulation time, $t_{\max }$ & $\mathrm{a}$ & 15 & - & Constant & [24] \\
\hline Critical chloride content, $c_{\mathrm{cr}}$ & $\%$ & 0.12 & 0.6 & Log-normal & [47] \\
\hline Diffusion coefficient, $D$ & $\mathrm{~mm}^{2} / \mathrm{s}$ & Variable & 0.2 & Log-normal & {$[27]$} \\
\hline Cover thickness, $x$ & $\mathrm{~mm}$ & 30 & 0.05 & Normal & [27] \\
\hline Temperature, Temp & ${ }^{\circ} \mathrm{C}$ & 20 & 0.02 & Normal & - \\
\hline Longitudinal reinforcement diameter, $d_{1}$ & $\mathrm{~mm}$ & $18 / 20$ & 0.01 & Normal & {$[41]$} \\
\hline Stirrup diameter, $d_{\mathrm{s}}$ & $\mathrm{mm}$ & 10 & 0.01 & Normal & {$[41]$} \\
\hline Column width, $b_{\mathrm{c}}$ & $\mathrm{mm}$ & 400 & 0.02 & Normal & {$[41]$} \\
\hline Beam height, $h_{\mathrm{b}}$ & $\mathrm{mm}$ & 400 & 0.02 & Normal & {$[41]$} \\
\hline Beam width, $b_{\mathrm{b}}$ & $\mathrm{mm}$ & 250 & 0.02 & Normal & {$[41]$} \\
\hline Concrete strength, $f_{c}$ & $\mathrm{MPa}$ & 30 & 0.2 & Log-normal & {$[41]$} \\
\hline Steel yield strength, $f_{\mathrm{y}}$ & $\mathrm{MPa}$ & 335 & 0.05 & Log-normal & {$[41]$} \\
\hline Distance between stirrups, $s$ & $\mathrm{~mm}$ & 100 & 0.1 & Normal & - \\
\hline Frictional coefficient of interface, $\mu$ & - & $0.6 / 1.2$ & - & Constant & {$[36]$} \\
\hline Axial force, $N$ & $\mathrm{kN}$ & 300 & - & Constant & - \\
\hline
\end{tabular}

shorter time before corrosion initiates. However, such influence is not linear, as the curve of Case 1 $\left(D=5 \times 10^{-6} \mathrm{~mm}^{2} / \mathrm{s}\right)$ is quite close to that of Case 2 $\left(D=1 \times 10^{-5} \mathrm{~mm}^{2} / \mathrm{s}\right)$. By examining with different diffusion coefficients, such relationship can be better described as Figure 9. In the figure, all the service life is normalized by that of the cast in situ group $\left(D=1 \times 10^{-6} \mathrm{~mm}^{2} / \mathrm{s}\right)$. It is clear that the influence of diffusivity can be great when the coefficient is comparatively low, and after reaching a certain value, $8 \times 10^{-6} \mathrm{~mm}^{2} / \mathrm{s}$, the time of corrosion initiation can be short enough and no longer sensitive to the diffusivity.

3.3. Prediction of Serviceability Limit State. In most engineering standards, the crack width threshold to define SLS is $0.2 \mathrm{~mm}$ or $0.3 \mathrm{~mm}$, and the latter is chosen herein. At a given corrosion depth, the corrosion level in the smaller bar is higher, and thus the width of corrosion-induced crack is larger. Therefore, only the cracks along the horizontal bars $(d=18 \mathrm{~mm})$ are investigated, and the exact time of SLS can be determined as 18.0, 14.9, 6.6, and 5.6 years for each group, respectively (shown in Figure 10). Even though diffusion coefficient is not directly involved in the corrosion model, its influence is still considerable. As is shown in Figure 8, when the coefficient increases from $1 \times 10^{-6} \mathrm{~mm}^{2} / \mathrm{s}$ to $1 \times 10^{-5} \mathrm{~mm}^{2} / \mathrm{s}$, the life of serviceability limit state will be shortened by more than $45 \%$. Similar to that of corrosion initiation, such relationship is nonlinear (Figure 11).

By subtracting the initiation stage from the total time, the length of the propagation stage can further be calculated, and they are $7.5,7.6,1.9$, and 2.0 years, respectively. The significantly shooter time at the interface can be explained by its higher pitting factor. As is mentioned before, such highly localized corrosion is largely due to the earlier corrosion 


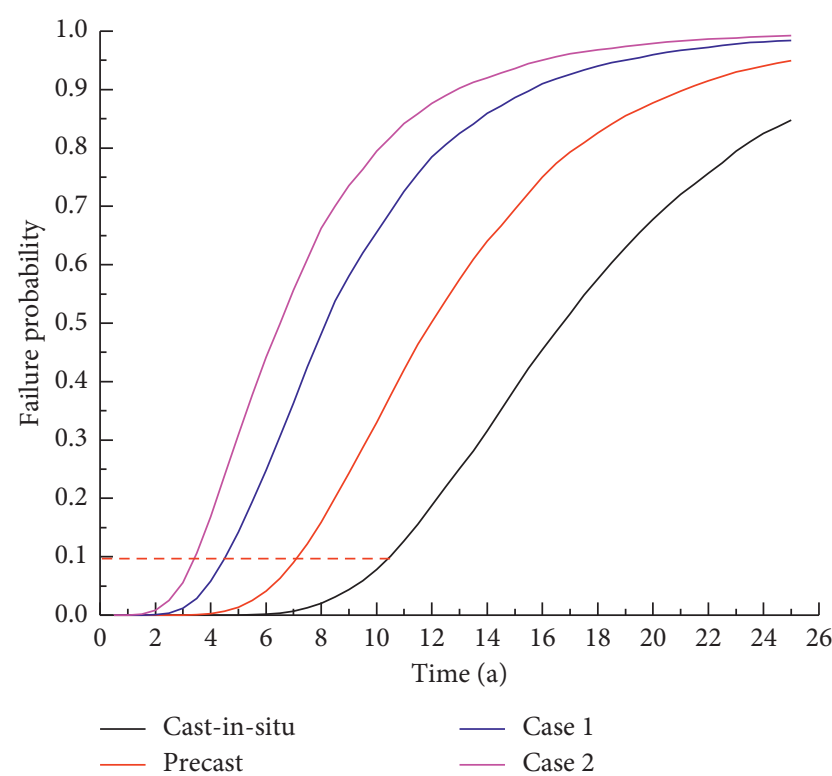

FIgURE 8: Time-variant probability of corrosion initiation.

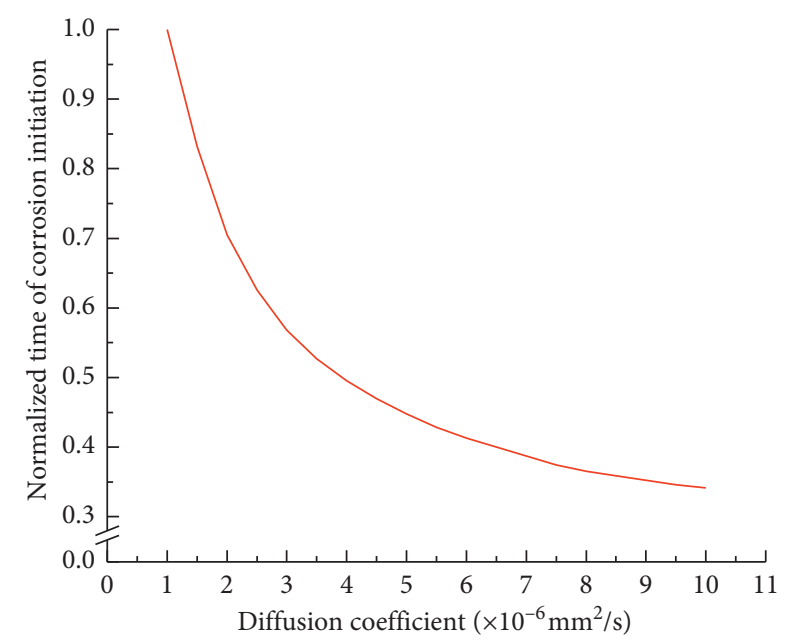

FIGURE 9: Relationship between corrosion initiation and diffusion coefficient.

initiation there and the large cathode corrosion system formed after. From this perspective, diffusion coefficient can also influence the following propagation stage through the natural connection in the deterioration mechanism.

3.4. Prediction of Residual Shear Bearing Capacity. Using the aforementioned probabilistic framework, the evolution of residual shear bearing capacities of each part can further be analyzed based on the corrosion level, and the statistical properties at different time are included in Table 3. From the comparison of absolute values, it is clear that the shear failure is controlled by failure in components, even after considering deterioration. However, it is worth noticing that the interface shear strength in beam is quite close to that of the component when $t=50 \mathrm{a}$. Considering its significantly larger reduction rate, interface shear failure may be the dominant mode in some cases.

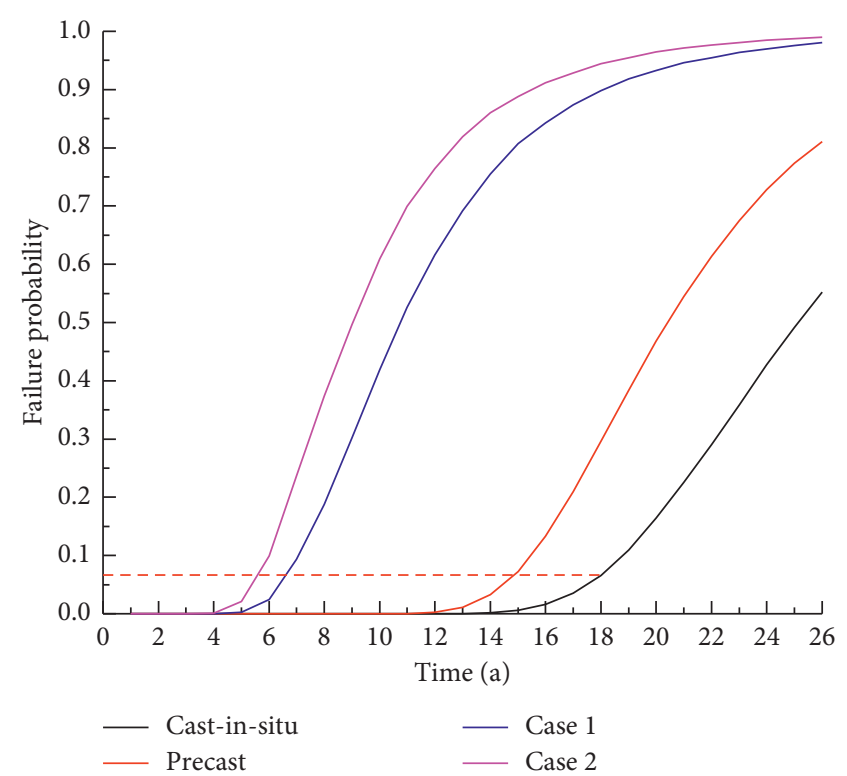

Figure 10: Time-variant probability of serviceability limit state $(d=18 \mathrm{~mm})$.

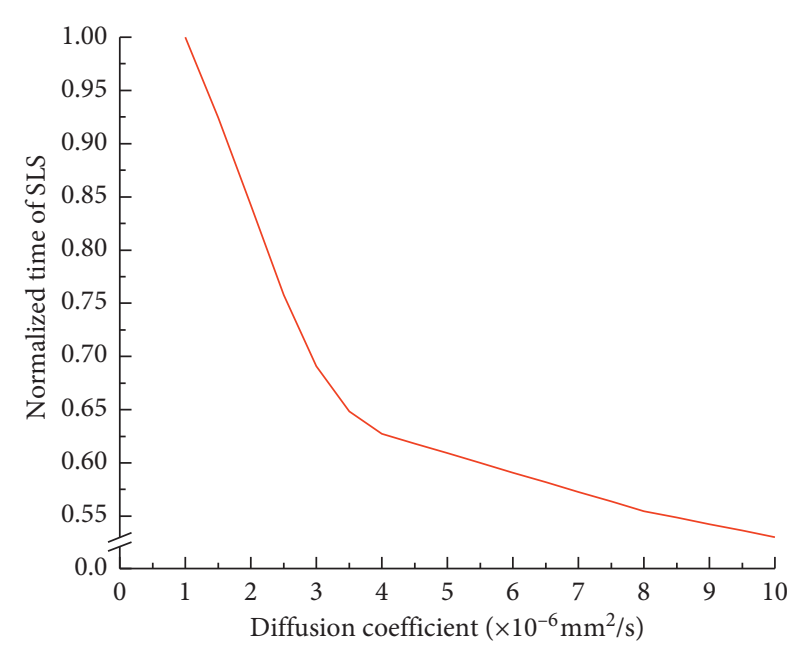

FIGURE 11: Relationship between SLS and diffusion coefficient $(d=18 \mathrm{~mm}, \alpha=8)$.

By choosing the means as representation and normalizing them with their respective original values $(t=0)$, the reduction trends of shear bearing capacities can be better expressed as Figure 12. The capacities of precast components change little in the first ten years. This is because corrosion initiates late there, and the corrosion levels are extremely low at that time. In comparison, interfacial shear capacities deteriorate fast in the whole process, which is the result of earlier and more localized corrosion there. Furthermore, beams deteriorates faster than columns, whether in the component or at the interface. The former can be explained as the concrete strength increases produced by axial compression, while the latter is because the friction induced by axial force takes a large proportion in the interface shear strength, and it is not influenced by corrosion in the model. 
TABLE 3: Statistical properties of residual shear capacity (unit: kN).

\begin{tabular}{|c|c|c|c|c|c|c|c|c|c|c|c|c|}
\hline & \multicolumn{2}{|c|}{ Column } & \multicolumn{2}{|c|}{$\begin{array}{c}\text { Column interface, } \\
\text { Case } 1\end{array}$} & \multicolumn{2}{|c|}{$\begin{array}{c}\text { Column interface, } \\
\text { Case } 2\end{array}$} & \multicolumn{2}{|c|}{ Beam } & \multicolumn{2}{|c|}{$\begin{array}{c}\text { Beam interface, } \\
\text { Case } 1\end{array}$} & \multicolumn{2}{|c|}{$\begin{array}{c}\text { Beam interface, } \\
\text { Case } 2\end{array}$} \\
\hline & Mean & $\mathrm{COV}$ & Mean & $\mathrm{COV}$ & Mean & $\mathrm{COV}$ & Mean & $\mathrm{COV}$ & Mean & $\mathrm{COV}$ & Mean & $\mathrm{COV}$ \\
\hline$t=0 \mathrm{a}$ & 305.7 & 0.120 & 832.4 & 0.087 & 832.4 & 0.087 & 248.3 & 0.141 & 626.6 & 0.146 & 626.6 & 0.146 \\
\hline$t=10 \mathrm{a}$ & 305.5 & 0.120 & 823.1 & 0.089 & 817.3 & 0.090 & 248.0 & 0.141 & 616.0 & 0.148 & 609.8 & 0.146 \\
\hline$t=20 \mathrm{a}$ & 300.5 & 0.120 & 769.7 & 0.096 & 758.1 & 0.095 & 242.6 & 0.142 & 568.1 & 0.148 & 558.8 & 0.146 \\
\hline$t=30 \mathrm{a}$ & 291.1 & 0.120 & 698.2 & 0.099 & 684.3 & 0.097 & 232.3 & 0.144 & 512.3 & 0.149 & 500.9 & 0.138 \\
\hline$t=40 \mathrm{a}$ & 280.2 & 0.121 & 618.8 & 0.103 & 604.1 & 0.100 & 220.0 & 0.145 & 438.7 & 0.152 & 423.6 & 0.151 \\
\hline$t=50 \mathrm{a}$ & 268.3 & 0.122 & 538.9 & 0.108 & 524.7 & 0.103 & 206.4 & 0.146 & 349.9 & 0.184 & 333.6 & 0.181 \\
\hline
\end{tabular}

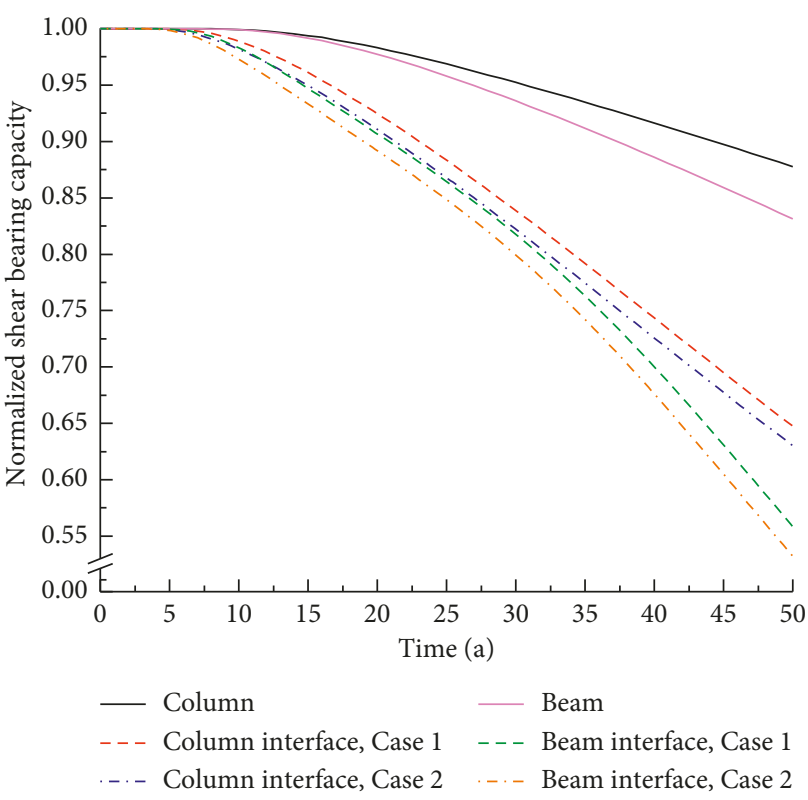

FIGURE 12: Decreasing shear bearing capacities with time.

3.5. Prediction of Residual Flexural Capacity. In some experimental investigations $[17,61,62]$, flexural failure at the beam/column end can be the failure mode for frames under seismic impact. Therefore, the flexural bearing capacity is another crucial aspect when considering ultimate limit state. To better reveal the difference between PC and cast in situ structures, two additional group with lower pitting factor ( $\alpha=4)$ are set to conduct the same analysis as PC beams/ columns, and the results are concluded in Table 4. Following the "strong column, weak beam" design philosophy, it is natural that the beam has lower capacity.

Similar to shear bearing capacity, there is little difference between Case 1 and Case 2, revealing that the influence of interface diffusivity is not so significant in the range from $5 \times 10^{-6}$ to $1 \times 10^{-5} \mathrm{~mm}^{2} / \mathrm{s}$. Instead, the influence of the pitting factor is significant (shown in Figure 13). Now that the large pitting factor is caused by different diffusivity between interface and substrate concrete, and it is more important to fill the diffusivity gap from the perspective of ULS.

By comparing the normalized residual flexural and shear strengths of Case 1, it is clear that flexural bearing capacity of column or beam is more sensitive to steel corrosion at the interface, regardless of the type of the component (shown in Figure 14). An explanation to this is the different contribution of materials under these two circumstances. Both concrete and steel can work to transfer shear force, while only steel works in the tensile area once concrete cracks under flexural loads. Therefore, flexural failure can be controlled by steel yielding, making the corrosion-induced strength and cross section loss more fatal in this condition.

\section{Further Discussion}

The results gained in the former section suggest that the sensitivity of diffusion coefficient decreases with the increase of its value and development of the propagation stage. For the first limit state, steel depassivation, the sensitivity is quite high, especially when the value is in the range which is common for ordinary structural concrete. As for SLS and ULS, even though they are not directly connected to the interface diffusivity and thus have a lower sensitivity, the influence is still considerable, owing to the natural connection between different stages of the deterioration process. Therefore, the diffusivity at the interface is crucial for PC structures, and there is a vital importance to control it to gain an elongate service life. Both the optimization of mixture proportion and additional structural measurements can be considered as solutions. For example, surface treatments such as wire brushing can not only increase the roughness and thus gain better mechanical performance [68] but also gain higher tortuosity of transportation path, which may retard the penetration of chloride ions effectively.

Due to such sensitivity, PC structures may be of shorter service life than those of cast in situ, especially in terms of corrosion initiation and SLS. For these two limit states, the failure first occurs at the grout connection interface, where the diffusion coefficient and pitting factors are relatively higher. However, when it comes to the potential shear failure under horizontal seismic load, the existence of interface turns to have little influence, as the failure first occurs in the components. This result is reasonable and in accordance with the aforementioned research without considering corrosion [69]. On the contrary, this is partly related to the perdition model herein. Due to the lack of experimental results, only the reductions of steel cross section, steel strength, and concrete cohesion area are considered in the interface shear model, while the crucial frictional coefficient and the upper bound of shear strength is a constant during the whole process. In fact, the corrosion production may work as lubricant [70] and the corrosion-induced cracks can also cause damage to the adjacent concrete, which may decrease the values of aforementioned two parameters. Therefore, the interface shear bearing capacity may be overestimated herein. 
TAвLE 4: Statistical features of residual flexural capacity (unit: $\mathrm{kN} \cdot \mathrm{m}$ ).

\begin{tabular}{lccccccccccccc}
\hline & \multicolumn{2}{c}{$\begin{array}{c}\text { Column, } \\
\text { monolithic }\end{array}$} & \multicolumn{2}{c}{ Column, } & \multicolumn{2}{c}{ Column, } & \multicolumn{2}{c}{ Beam, } & \multicolumn{2}{c}{$\begin{array}{c}\text { Beam, } \\
\text { Case 1 }\end{array}$} & \multicolumn{2}{c}{ Case 2 } & \multicolumn{2}{c}{$\begin{array}{c}\text { Beam, } \\
\text { Case 2 }\end{array}$} \\
& Mean & COV & Mean & COV & Mean & COV & Mean & COV & Mean & COV & Mean & COV \\
\hline$t=0 \mathrm{a}$ & 120.0 & 0.087 & 120.0 & 0.087 & 120.0 & 0.087 & 77.8 & 0.105 & 77.8 & 0.105 & 77.8 & 0.105 \\
$t=10 \mathrm{a}$ & 120.0 & 0.087 & 118.8 & 0.088 & 117.9 & 0.088 & 77.7 & 0.105 & 76.4 & 0.107 & 75.5 & 0.109 \\
$t=20 \mathrm{a}$ & 118.5 & 0.087 & 110.0 & 0.096 & 108.0 & 0.095 & 761 & 0.107 & 67.3 & 0.128 & 65.2 & 0.129 \\
$t=30 \mathrm{a}$ & 115.3 & 0.088 & 97.2 & 0.108 & 94.7 & 0.106 & 72.7 & 0.109 & 54.3 & 0.163 & 51.8 & 0.161 \\
$t=40 \mathrm{a}$ & 111.1 & 0.089 & 82.9 & 0.123 & 80.2 & 0.120 & 68.4 & 0.113 & 40.4 & 0.214 & 37.8 & 0.211 \\
$t=50 \mathrm{a}$ & 106.3 & 0.090 & 68.4 & 0.142 & 65.8 & 0.137 & 63.5 & 0.118 & 27.8 & 0.263 & 26.0 & 0.240 \\
\hline
\end{tabular}

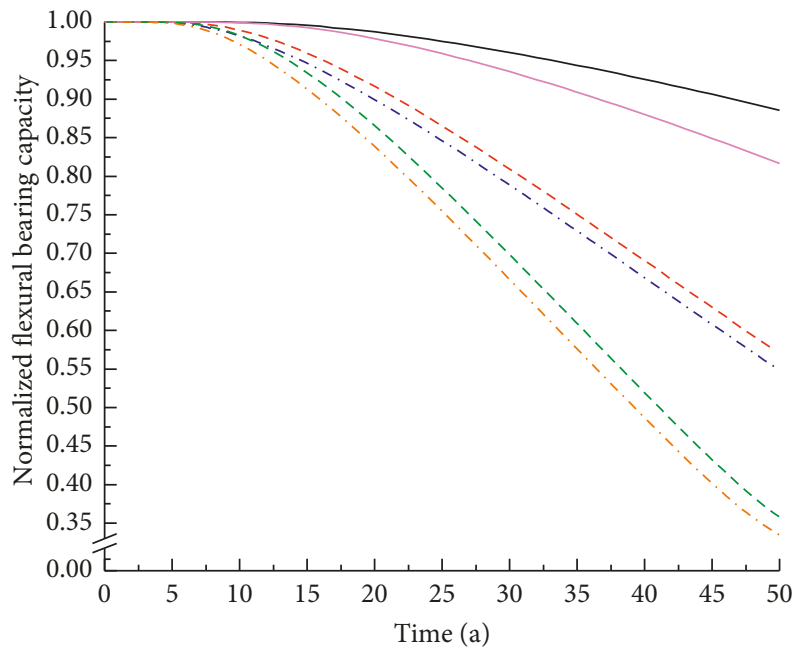

$$
\begin{array}{lll}
- \text { Column, monolithic } & - & \text { Beam, monolithic } \\
\ldots-- \text { Column, Case 1 } & --- & \text { Beam, Case } 1 \\
\ldots \text { _- } \text { Column, Case } 2 & \ldots- & \text { Beam, Case } 2
\end{array}
$$

Figure 13: Decreasing flexural capacities with time.

Unlike shear failure, flexural failure is more influenced by high diffusivity and pitting factor around the interface, especially the latter. By simplifying the seismic impact as a horizontal force at the end of upper column, as many experimental researches did $[17,61]$, it is clear that the failure of the example is controlled by flexural bearing capacity at the beam end. This result is reasonable, as the ductile flexural failure is preferred in engineering practice. Considering almost all the interfaces are located at the component end and the corrosion level there is higher, such deterioration may be critical for PC frames, making them less reliable than cast in situ structures. Therefore, it is crucial to control the diffusivity around the interface, not only for postponing corrosion initiation and SLS but also from the consideration of ULS and structural safety.

Furthermore, load cracks are also likely to form around the connection interface due to defects [69], high flexural moment [61, 71], and stiffness change caused by sleeves [17]. As cracks can dramatically increase diffusion [72], the durability problem around the connection interface can even be severer. However, the influence of load cracks, whether around the interface or in the precast components, is not considered herein, so the performance deterioration of PC structures under a combined effect of load and marine environment still needs to be clarified by further research.

\section{Conclusions}

The present study proposes a probabilistic framework to consider the uncertainty of parameters and predict the performance evolution of RC structures in the marine environment. On the basis of the framework, the influences of the diffusivity at grout connection interface are analyzed through a specified beam-column joint sample and the special characteristics of PC structures are further addressed. The following remarks can be drawn:

(1) By applying the path probability model (PPM), the whole process of chloride-induced deterioration can be analyzed in an effective way for both PC and cast in situ RC structures. Three limit states, including steel depassivation, serviceability limit state, and ultimate limit state, can be predicted based on the time-variant failure probability and the welldeveloped reliability theory.

(2) Potential defects at the connection interface can trigger earlier and higher localized corrosion there. Consequently, both the SLS and bearing capacity deterioration occur in advance compared to the cast in situ structures, even though they are not directly controlled by diffusion coefficient.

(3) Among all three limit states, corrosion initiation is the most sensitive to the diffusivity at connection interface of PC structures, followed by SLS. Both of the corresponding service life decreases with the increase of diffusivity, especially in the typical value range for concrete.

(4) Compared to shear failure, flexural failure is more sensitive to corrosion at the interface, especially the potential localized corrosion induced by high diffusivity. Since flexural failure is the suggested failure mode in structures, it is important to lower the diffusivity of interface and avoid the potential localized corrosion there.

\section{Appendix}

\section{A. Calculation of Steel Section Loss}

By assuming the corrosion pit is part of a sphere, the steel section loss $\Delta A_{\mathrm{s}}$ can be calculated with the maximum corrosion depth $p_{\max }$ and the original diameter of reinforcement. $d_{0}$ 


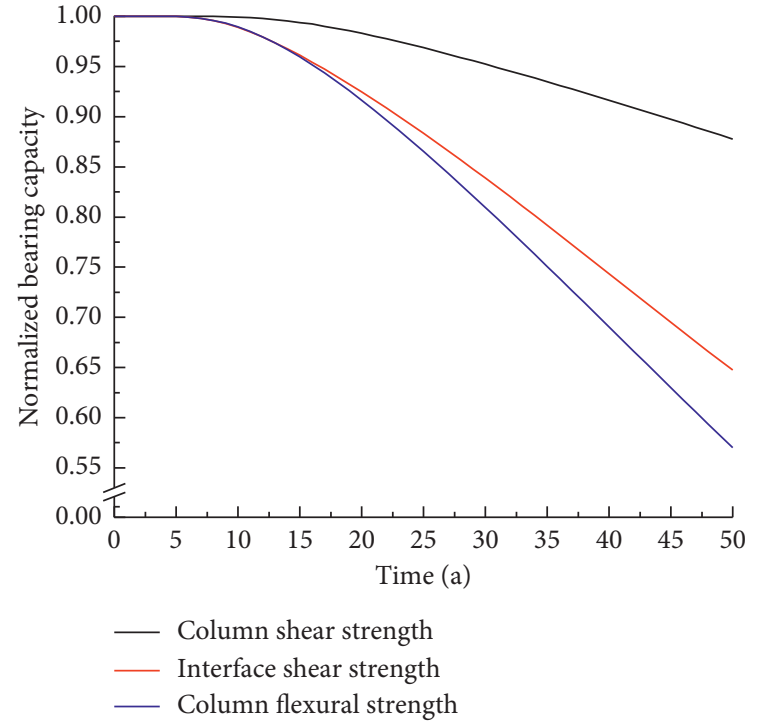

(a)

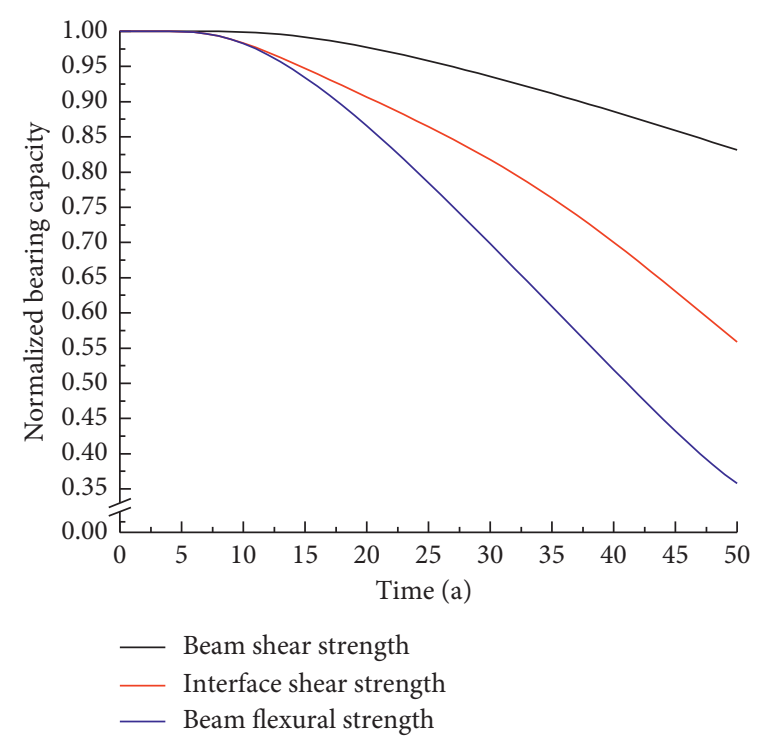

(b)

FIGURE 14: Decreasing residual bearing capacities with time. (a) Column. (b) Beam.

$$
\begin{aligned}
& \Delta A_{\mathrm{s}}= \begin{cases}A_{1}+A_{2}, & p_{\max } \leq \frac{d_{0}}{\sqrt{2}}, \\
\frac{\pi d_{0}^{2}}{4}-A_{1}+A_{2}, & \frac{d_{0}}{\sqrt{2}}<p_{\max } \leq d_{0}, \\
\frac{\pi d_{0}^{2}}{4}, & p_{\max } \geq d_{0},\end{cases} \\
& A_{1}=\frac{1}{2}\left(\theta_{1}\left(\frac{d_{0}}{2}\right)^{2}-a\left|\frac{d_{0}}{2}-\frac{p_{\max }^{2}}{d_{0}}\right|\right), \\
& A_{2}=\frac{1}{2}\left(\theta_{2} p_{\max }^{2}-\frac{a p_{\max }^{2}}{d_{0}}\right),
\end{aligned}
$$

where $\theta_{1}, \theta_{2}$, and $a$ can be further calculated using the geometric relations shown in Figure 15:

$$
\begin{aligned}
& a=2 p_{\max } \sqrt{1-\left(\frac{p_{\max }}{d_{0}}\right)^{2}}, \\
& \theta_{1}=2 \arcsin \left(\frac{a}{d_{0}}\right) \theta_{2}=2 \arcsin \left(\frac{a}{2 p_{\max }}\right) .
\end{aligned}
$$

The corrosion level $\rho$ can be further determined through the following equation:

$$
\rho=\frac{\Delta A_{\mathrm{s}}}{A_{0}}=\frac{4 \Delta A_{\mathrm{s}}}{\pi d_{0}^{2}} .
$$

\section{B. Bearing Capacity Models for Corroded Components}

As is mentioned in 2.5, three points, including axial compression point, pure bending point, and balanced failure

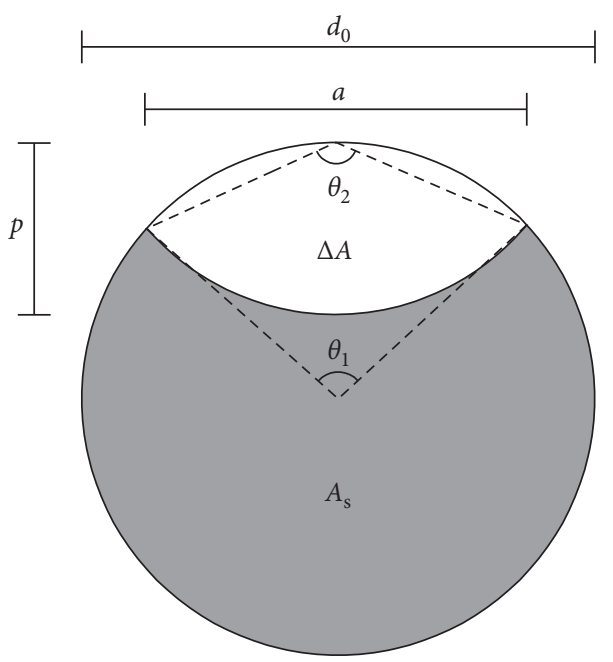

FIGURE 15: Pit configuration.

point, are crucial for the M-N curve [64]. Since the exact physical meanings of these points are different, they should be separately discussed.

Without the existence of external moment, axial compression point is a comparatively simple state and the bearing capacity can be regarded as the combination of concrete contribution and steel reinforcement contribution. In the model, concrete can further be divided into three parts according to their confinement statescover part (denoted by $A_{1 \mathrm{c}}$ ), core part (denoted by $A_{3 \mathrm{c}}$ ), and the part between them (denoted by $A_{2 \mathrm{c}}$ ). Given the diameters of stirrups $\left(d_{\mathrm{s}}\right)$ and longitudinal bars $\left(d_{1}\right)$, as well as cover thickness $(x)$, areas of all three parts can be calculated using the geometrical relations (shown in Figure 16). Therefore, the bearing capacity can be written as follows: 


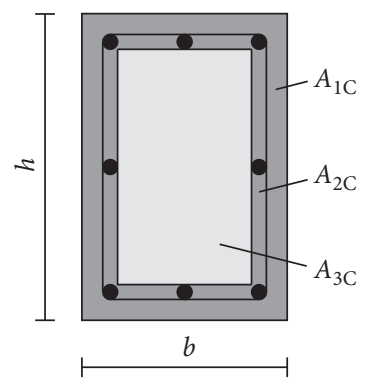

FIgURE 16: Different parts of concrete under axial compression.

$$
N_{\text {axial }}=\psi f_{\mathrm{c}} A_{1 \mathrm{c}}+\psi f_{\mathrm{cc}} A_{2 \mathrm{c}}+f_{\mathrm{cc}} A_{3 \mathrm{c}}+A_{1, \mathrm{r}}\left(1-\alpha_{\mathrm{s}} \rho\right) f_{\mathrm{y}}
$$

where $\psi$ is the attenuation factor to describe the loss of concrete compression strength due to corrosion-induced cracking; $f_{\mathrm{c}}$ and $f_{\mathrm{cc}}$ is the concrete compression strength without and with confinement; $A_{\mathrm{l}, \mathrm{r}}$ is the total residual area of longitudinal bars in $\mathrm{mm}^{2}$; and the others, including $\alpha_{\mathrm{s}}, \rho$, and $f_{\mathrm{y}}$, have the same meaning as those in equation (12).

$$
\begin{aligned}
& A_{1 \mathrm{c}}=(2 b x+2 h x)-4 x^{2}, \\
& A_{2 \mathrm{c}}=b h-A_{1 \mathrm{c}}-A_{3 \mathrm{c}}, \\
& A_{3 \mathrm{c}}=\left(b-2 x-2 d_{\mathrm{s}}-2 d_{1}\right)\left(h-2 x-2 d_{\mathrm{s}}-2 d_{1}\right),
\end{aligned}
$$

where $\psi$ and $f_{\mathrm{cc}}$ in equation (B.1) can be further defined as follows:

$$
\begin{aligned}
\psi & =\frac{1}{1+\left(300 \pi n_{\mathrm{bar}} p / b\right)} \\
f_{\mathrm{cc}} & =\left[1+\frac{0.45 \pi d_{\mathrm{s}}^{2}(1-\rho) C\left(1-\alpha_{\mathrm{s}} \rho\right) f_{\mathrm{yt}}}{s A_{3 \mathrm{c}} f_{\mathrm{c}}}\right] f_{\mathrm{c}},
\end{aligned}
$$

where $n_{\mathrm{bar}}$ is the number of bars in the compression region, $p$ is the corrosion depth calculated by equation (7), $C$ is the length of one stirrup in $\mathrm{mm}$, and $s$ is the space between stirrups in $\mathrm{mm}$.

As for pure bending point, its bearing capacity can be determined based on classical model for flexural analysis. For components with symmetric reinforcement, compressed bars hardly yield at the ultimate strength, so the equivalent height of the compression zone in concrete $\left(x_{\mathrm{e}}\right)$ can only be assumed as twice of the distance between the resultant force point of reinforcement and the compression edge of the section $\left(a_{\mathrm{s}}^{\prime}\right)$. Therefore, the capacity can be expressed as

$$
\begin{aligned}
M_{\text {bending }} & =A_{\mathrm{l}, \mathrm{re}}\left(1-\alpha_{\mathrm{s}} \rho\right) f_{\mathrm{y}}\left(h-2 a_{\mathrm{s}}^{\prime}\right) \\
& =A_{\mathrm{l}}(1-\rho)\left(1-\alpha_{\mathrm{s}} \rho\right) f_{\mathrm{y}}\left(h-2 x-2 d_{\mathrm{s}}-d_{\mathrm{l}}\right) .
\end{aligned}
$$

According to its definition, both steel bars and concrete reach their ultimate strength at the balanced failure point. The relative height of the compression zone $\xi$ is relative to the elastic modulus and yield strength of reinforcement, and it can be expressed as

$$
\xi=\frac{x_{\mathrm{r}}}{h_{0}}=\frac{0.8}{1+\left(\left((1+0.27152 \rho)\left(1-\alpha_{\mathrm{s}} \rho\right) f_{\mathrm{y}}\right) / 0.0033 E_{\mathrm{s}}\right)},
$$

where $E_{\mathrm{s}}$ is the elastic modulus of steel, which is $210 \mathrm{GPa}$ and hardly influenced by corrosion. Therefore, the bearing capacity at the balanced failure point is

$$
\begin{aligned}
& N_{\text {balance }}=\xi h_{0} f_{\mathrm{cc}} b+A_{\mathrm{l}}(1-\rho)\left(1-\alpha_{\mathrm{s}} \rho\right) f_{\mathrm{y}}, \\
& M_{\text {balance }}=A_{1} f_{\mathrm{y}}\left(h_{0}-\frac{h}{2}\right)+\xi h_{0} f_{\mathrm{cc}} b\left(\frac{h}{2}-\frac{\xi h_{0}}{2}\right) .
\end{aligned}
$$

\section{Data Availability}

The data used to support the findings of this study are included within the article.

\section{Conflicts of Interest}

The authors declare that they have no conflicts of interest.

\section{Acknowledgments}

The financial support from the National Key Research and Development Program of China (no. 2016YFC0701400), the National Science Foundation of China (no. 51820105012), the Fundamental Research Funds for the Central Universities of China (no. 2019 FZA4017), and the research project for traffic engineering construction from Transportation Department of Zhejiang (no. 2018035) is gratefully acknowledged.

\section{References}

[1] B. Tu, Z. Fang, Y. Dong, and D. M. Frangopol, “Time-variant reliability analysis of widened deteriorating prestressed concrete bridges considering shrinkage and creep," Engineering Structures, vol. 153, pp. 1-16, 2017.

[2] F. Faleschini, M. A. Zanini, and L. Hofer, "Reliability-based analysis of recycled aggregate concrete under carbonation," Advances in Civil Engineering, vol. 2018, Article ID 4742372, 11 pages, 2018.

[3] K. Zhang and J. Xiao, "Time-dependent reliability analysis on carbonation behavior of recycled aggregate concrete based on gamma process," Construction and Building Materials, vol. 158, pp. 378-388, 2018.

[4] W. Jin and Y. Zhao, Durability of Concrete Structures, Chinese Science Press, Beijing, 2nd edition, 2014, in Chinese.

[5] H. Zhang, "Durability reliability analysis for corroding concrete structures under uncertainty," Mechanical Systems and Signal Processing, vol. 101, pp. 26-37, 2018.

[6] X. Zhang and B. Li, "Shear-strength capacity assessment of corroded reinforced concrete beam-column joints," Journal of Performance of Construction Facilities, vol. 32, no. 5, article 04018067, 2018.

[7] N. S. Vu and B. Li, "Seismic performance of flexural reinforced concrete columns with corroded reinforcement," ACI Structural Journal, vol. 115, no. 5, pp. 1253-1266, 2018. 
[8] S. Yang and X. Liu, "Seismic analytical model of shear strength for corroded RC column," Materials and Structures, vol. 48, no. 8, pp. 2671-2684, 2015.

[9] S. V. Ngoc, B. Yu, and B. Li, "Prediction of strength and drift capacity of corroded reinforced concrete columns," Construction and Building Materials, vol. 115, pp. 304-318, 2016.

[10] G. Ma, H. Li, and H.-J. Hwang, "Seismic behavior of lowcorroded reinforced concrete short columns in an over 20year building structure," Soil Dynamics and Earthquake Engineering, vol. 106, pp. 90-100, 2018.

[11] K. Tuutti, "Corrosion of steel in concrete," in CBI Research Report, p. 468, Swedish Cement and Concrete Research Institute, Stockholm, Sweden, Swedish Cement and Concrete Research Institute, 1982.

[12] C. Q. Li, "Reliability based service life prediction of corrosion affected concrete structures," Journal of Structural Engineering-ASCE, vol. 130, no. 10, pp. 1570-1577, 2004.

[13] J. Hackl, Generic Framework for Stochastic Modeling of Reinforced Concrete Deterioration Caused by Corrosion, Norwegian University of Science and Technology, Trondheim, Norway, 2013.

[14] D. R. Vieira, A. L. R. Moreira, J. L. Calmon, and W. K. Dominicini, "Service life modeling of a bridge in a tropical marine environment for durable design," Construction and Building Materials, vol. 163, pp. 315-325, 2018.

[15] PCI, PCI Design Handbook, Precast/Prestressed Concrete Institute, Chicago, IL, USA, 7th edition, 2010.

[16] I. Segura, S. Cavalaro, A. de la Fuente, A. Aguado, and V. Alegre, "Service-life assessment of existing precast concrete structure exposed to severe marine conditions," Journal of Performance of Constructed Facilities, vol. 30, no. 3, article 04015036, 2016.

[17] H. Liu, Q. Yan, and X. Du, "Seismic performance comparison between precast beam joints and cast-in-place beam joints," Advances in Structural Engineering, vol. 20, no. 9, pp. 12991314, 2016.

[18] C. Di Bella and B. A. Graybeal, "Volume stability and cracking potential of prebagged, cement-based nonshrink grouts for field-cast connections," Transportation Research Record: Journal of the Transportation Research Board, vol. 2441, no. 1, pp. 6-12, 2018.

[19] DuraCrete, "Duracrete final technical report, probabilistic performance based durability design of concrete structures," The European Union Brite EuRam 3 contract BRPR-CT950132, Project BE95-1347, Report no. BE95-1347/R17, 2000.

[20] J. R. Clifton, Service Life Prediction-State-of-the-Art Report, Report ACI 365.1R-00, American Concrete Institute (ACI), Famington Hills, MI, USA, 2001.

[21] S. Morinaga, "Prediction of service life of reinforced concrete buildings based on the corrosion rate of reinforcing steel," in Proceedinds of the 5th International Conference on Durability of Building Materials and Components, Brighton, UK, November 1990.

[22] I. Stipanovic Oslakovic, D. Bjegovic, and D. Mikulic, "Evaluation of service life design models on concrete structures exposed to marine environment," Materials and Structures, vol. 43, no. 10, pp. 1397-1412, 2010.

[23] L. Pang and Q. Li, "Service life prediction of RC structures in marine environment using long term chloride ingress data: comparison between exposure trials and real structure surveys," Construction and Building Materials, vol. 113, pp. 979-987, 2016.

[24] Life-365 Consortium III, "Life-365 service life prediction model and computer program for predicting the service life and life-cycle cost of reinforced concrete exposed to chlorides," 2018.

[25] M. B. Anoop, B. K. Raghuprasad, and K. Balaji Rao, “A refined methodology for durability-based service life estimation of reinforced concrete structural elements considering fuzzy and random uncertainties," Computer-Aided Civil and Infrastructure Engineering, vol. 27, no. 3, pp. 170-186, 2012.

[26] M. G. Stewart and D. V. Rosowsky, "Time-dependent reliability of deteriorating reinforced concrete bridge decks," Structural Safety, vol. 20, no. 1, pp. 91-109, 1998.

[27] K. A. T. Vu and M. G. Stewart, "Structural reliability of concrete bridges including improved chloride-induced corrosion models," Structural Safety, vol. 22, no. 4, pp. 313-333, 2000.

[28] Q. Li, K. Li, X. Zhou, Q. Zhang, and Z. Fan, "Model-based durability design of concrete structures in Hong KongZhuhai-Macau sea link project," Structural Safety, vol. 53, pp. 1-12, 2015.

[29] L.-J. Wu, Y.-J. Zhou, X.-J. Kou, and M. Jiang, "Reliabilitybased service life prediction of existing concrete structures under marine environment," Journal of Central South University, vol. 22, no. 9, pp. 3608-3614, 2015.

[30] B. Yu, C.-L. Ning, and B. Li, "Probabilistic durability assessment of concrete structures in marine environments: reliability and sensitivity analysis," China Ocean Engineering, vol. 31, no. 1, pp. 63-73, 2017.

[31] G. de Vera, C. Antón, M. P. López, and M. A. Climent, "Depassivation time estimation in reinforced concrete structures exposed to chloride ingress: a probabilistic approach," Cement and Concrete Composites, vol. 79, pp. 21-33, 2017.

[32] S.-H. Jung, H.-M. Yang, K.-H. Yang, and S.-J. Kwon, "Maintenance for repaired RC column exposed to chloride attack based on probability distribution of service life," International Journal of Concrete Structures and Materials, vol. 12, no. 1, 2018.

[33] D.-H. Yang, G.-P. Li, T.-H. Yi, and H.-N. Li, "A performancebased service life design method for reinforced concrete structures under chloride environment," Construction and Building Materials, vol. 124, pp. 453-461, 2016.

[34] JCSS, JCSS Probabilistic Model Code, JCSS, Lyngby, Denmark, 2001, http://www.jcss.byg.dtu.dk.

[35] M. Collepardi, A. Marcialis, and R. Turriziani, "Penetration of chloride ions into cement pastes and concretes," Journal of the American Ceramic Society, vol. 55, no. 10, pp. 534-535, 1972.

[36] CEB-FIP, Fib Model Code for Concrete Structures 2010, International Federation for Structural Concrete (fib), Lausanne, Switzerland, 2013.

[37] L. Tang and L. O. Nilsson, "Chloride diffusivity in high strength concrete at different ages," Nordic Concrete Research Publication, vol. 11, pp. 162-171, 1992.

[38] S. Zhou, "Modeling chloride diffusion in concrete with a linear increase of surface chloride," ACI Materials Journal, vol. 111, no. 5, 2014.

[39] H. Yu et al., "Study on prediction of concrete service life I theoretical model," Journal of the Chinese Ceramic Society, vol. 6, pp. 686-690, 2002.

[40] N. Perez, Electrochemistry and Corrosion Science, Kluwer Academic Publishers, Boston, MA, USA, 2004.

[41] J. Hackl and J. Kohler, "Reliability assessment of deteriorating reinforced concrete structures by representing the coupled effect of corrosion initiation and progression by Bayesian networks," Structural Safety, vol. 62, pp. 12-23, 2016. 
[42] T. Liu and R. W. Weyers, "Modeling the dynamic corrosion process in chloride contaminated concrete structures," $\mathrm{Ce}$ ment and Concrete Research, vol. 28, no. 3, pp. 365-379, 1998.

[43] X. Song, Corrosion of Reinforcement in Reinforced Concrete Structures, Tsinghua University, Beijing, China, 1999, in Chinese.

[44] M. S. Darmawan, "Pitting corrosion model for reinforced concrete structures in a chloride environment," Magazine of Concrete Research, vol. 62, no. 2, pp. 91-101, 2010.

[45] B. Yu, L. Yang, M. Wu, and B. Li, "Practical model for predicting corrosion rate of steel reinforcement in concrete structures," Construction and Building Materials, vol. 54, pp. 385-401, 2014.

[46] M. Raupach, "Models for the propagation phase of reinforcement corrosion-an overview," Materials and Corrosion, vol. 57, no. 8, pp. 605-613, 2006.

[47] Y. Cao, Chloride Transport and Reliability-Based Service Life Prediction of Concrete under Load, China Building Materials Academy, Beijing, China, 2016, in Chinese.

[48] T. Vidal, A. Castel, and R. François, "Analyzing crack width to predict corrosion in reinforced concrete," Cement and Concrete Research, vol. 34, no. 1, pp. 165-174, 2004.

[49] H. Lin and Y. Zhao, "Predictive model of cracking propagation of reinforced concrete beam," Journal of Building Structures, vol. 35, pp. 248-253, 2014.

[50] J. A. Mullard and M. G. Stewart, "Corrosion-induced cover cracking: new test data and predictive models," ACI Structural Journal, vol. 108, no. 1, pp. 71-79, 2011.

[51] D. V. Val and L. Chernin, "Serviceability reliability of reinforced concrete beams with corroded reinforcement," Journal of Structural Engineering, vol. 135, no. 8, pp. 896-905, 2009.

[52] C. Andrade, C. Alonso, and F. J. Molina, "Cover cracking as a function of bar corrosion: part I-Experimental test," Materials and Structures, vol. 26, no. 8, pp. 453-464, 1993.

[53] MOHURD of China, GB/T 51231-2016 Engineering Code for Precast Concrete Structures, MOHURD of China, Beijing, China, 2016, in Chinese.

[54] A. P. Vatteri, K. Balaji Rao, and A. M. Bharathan, "Timevariant reliability analysis of RC bridge girders subjected to corrosion-shear limit state," Structural Concrete, vol. 17, no. 2, pp. 162-174, 2016.

[55] M. M. Kioumarsi, M. A. N. Hendriks, J. Kohler, and M. R. Geiker, "The effect of interference of corrosion pits on the failure probability of a reinforced concrete beam," Engineering Structures, vol. 114, pp. 113-121, 2016.

[56] Y. G. Du, L. A. Clark, and A. H. C. Chan, "Residual capacity of corroded reinforcing bars," Magazine of Concrete Research, vol. 57, no. 3, pp. 135-147, 2005.

[57] W. Jin, Corroded Concrete Structures, Chinese Science Press, Beijing, China, 2011.

[58] P. M. D. Santos and E. N. B. S. Júlio, "A state-of-the-art review on shear-friction," Engineering Structures, vol. 45, pp. 435448, 2012.

[59] D. Figueira, C. Sousa, R. Calçada, and A. Serra Neves, "Design recommendations for reinforced concrete interfaces based on statistical and probabilistic methods," Structural Concrete, vol. 17, no. 5, pp. 811-823, 2016.

[60] S. Kwon, K. Yang, and J. Mun, "Mechanical model for shear friction capacity of concrete at construction joints," Advances in Materials Science and Engineering, vol. 2018, Article ID 9264503, 12 pages, 2018.

[61] Q. Yan, T. Chen, and Z. Xie, "Seismic experimental study on a precast concrete beam-column connection with grout sleeves," Engineering Structures, vol. 155, pp. 330-344, 2018.
[62] A. Belleri and P. Riva, "Seismic performance and retrofit of precast concrete grouted sleeve connections," PCI Journal, vol. 57, no. 1, pp. 97-109, 2012.

[63] B. Feng, F. Xiong, J. Chen, W. Chen, and Y. Zhang, "Effects of postcast connection locations on the seismic performance of precast concrete frame joints," The Structural Design of Tall and Special Buildings, vol. 27, no. 18, article e1544, 2018.

[64] J. Xin, J. Zhou, F. Zhou, S. Yang, and Y. Zhou, "Bearing capacity model of corroded RC eccentric compression columns based on Hermite interpolation and Fourier fitting," Applied Sciences, vol. 9, no. 1, 2019.

[65] X. Wang, W. Jin, and Y. Yan, "Path probability model of corrosion-crack assessment for existing reinforced concrete structures," Journal of Zhejiang University-Engineering Science, vol. 44, no. 6, pp. 1191-1196, 2010, in Chinese.

[66] International Federation for Structural Concrete, Fib Bulletin No 34. Model Code for Service Life Design, International Federation for Structural Concrete, Lausanne, Switzerland, 2006.

[67] DOHURD-Zhejiang, "Technical specifications for durability of concrete structures," DOHURD, Hangzhou, China, DB33T1128-2016, 2016, in Chinese.

[68] M. E. Mohamad, I. S. Ibrahim, R. Abdullah, A. B. Abd. Rahman, A. B. H. Kueh, and J. Usman, "Friction and cohesion coefficients of composite concrete-to-concrete bond," Cement and Concrete Composites, vol. 56, pp. 1-14, 2015.

[69] E. Cavaco and J. Camara, "Experimental research on the behaviour of concrete-to-concrete interfaces subjected to a combination of shear and bending moment," Engineering Structures, vol. 132, pp. 278-287, 2017.

[70] A. A. Almusallam, A. S. Al-Gahtani, A. R. Aziz, and Rasheeduzzafar, "Effect of reinforcement corrosion on bond strength," Construction and Building Materials, vol. 10, no. 2, pp. 123-129, 1996.

[71] M. J. Ameli and C. P. Pantelides, "Seismic analysis of precast concrete bridge columns connected with grouted splice sleeve connectors," Journal of Structural Engineering, vol. 143, no. 2, article 04016176, 2017.

[72] C. Gu, G. Ye, and W. Sun, "A review of the chloride transport properties of cracked concrete: experiments and simulations," Journal of Zhejiang University Science A, vol. 16, no. 2, pp. 81-92, 2015. 


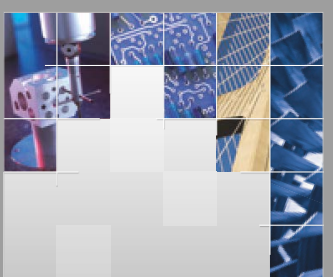

\section{Enfincering}
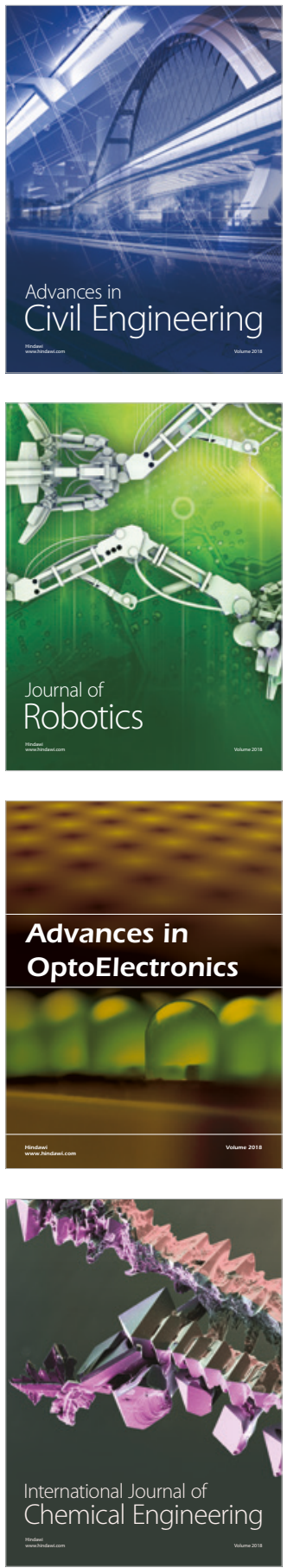

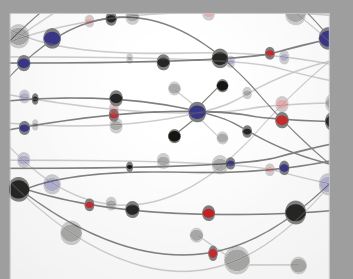

\section{Rotating \\ Machinery}

The Scientific World Journal

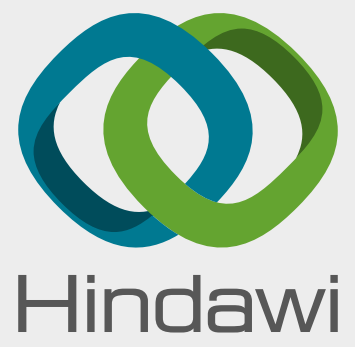

Submit your manuscripts at

www.hindawi.com
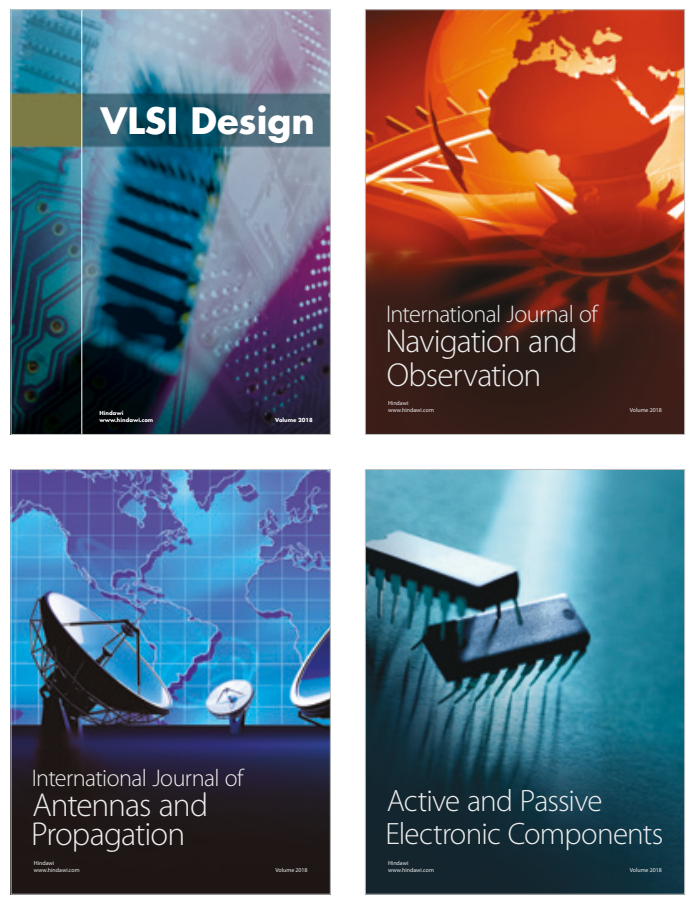
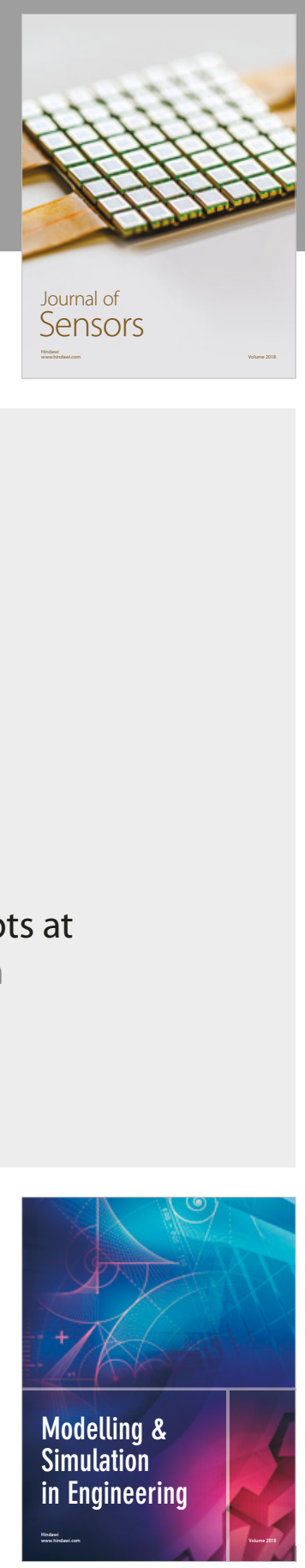

\section{Advances \\ Multimedia}
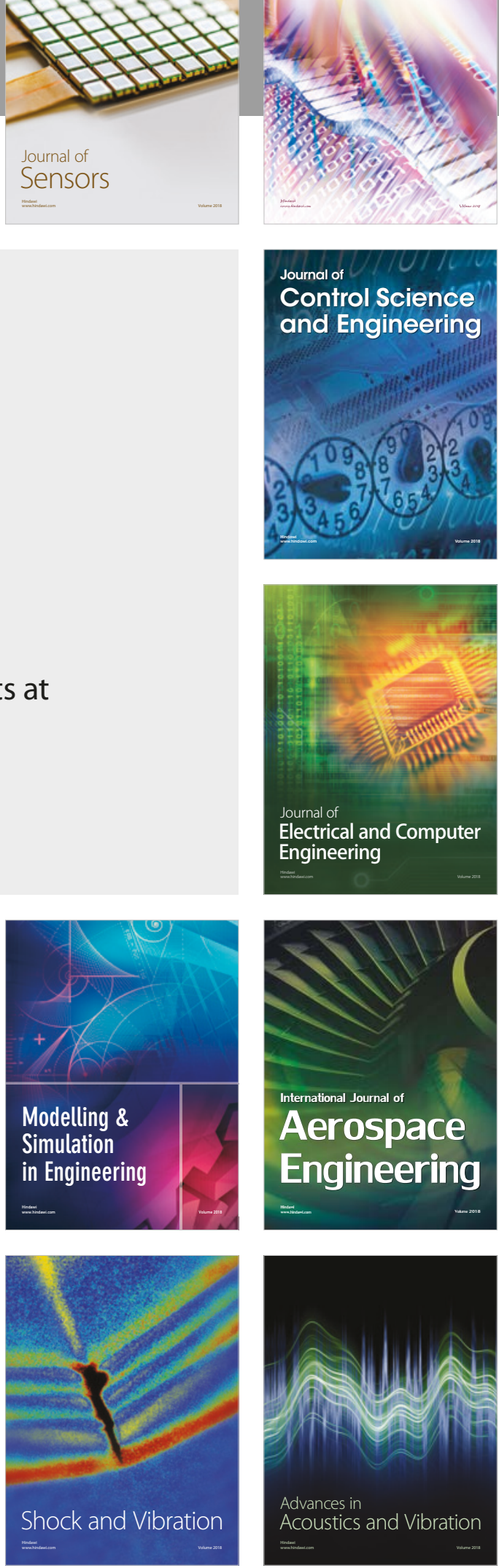